\title{
Distribuição espacial da freqüência de chuvas na região hidrográfica do Atlântico, Leste de Minas Gerais
}

\author{
Júlio C. F. de Melo Júnior ${ }^{1}$, Gilberto C. Sediyama ${ }^{2}$, Paulo A. Ferreira ${ }^{2}$, Brauliro G. Leal ${ }^{2} \&$ Rosandro B. Minusi ${ }^{2}$
}

\begin{abstract}
RESUMO
Este artigo, relacionado à segunda parte de um estudo abrangente da determinação de regiões homogêneas quanto a freqüência de chuvas no Leste do Estado de Minas Gerais, complementa a discussão em relação à distribuição geoespacial das regiões hidroclimaticamente homogêneas obtidas por meio da análise estatística multivariada. Neste trabalho, as variáveis fisiográficas: vegetação natural, orografia e direção do vento e os totais de chuva anual espacializados utilizando-se a técnica geoestatística de krigagem, são utilizadas com o intuito de interpretar a distribuição geoespacial dos grupos que representam as regiões com características homogêneas da freqüência de chuvas, na região hidrográfica em estudo. Em âmbito geral, o interpolador geoestatístico proporcionou boas estimativas dos totais de chuva média anual para a região estudada, exceto para as áreas nas quais a densidade de estações se apresentou reduzida. As variáveis fisiográficas e a superfície contínua de totais de chuva média anual justificaram a distribuição espacial dos grupos que representam as regiões hidroclimaticamente homogêneas, sendo que a orografia e as direções predominantes dos ventos a baixos níveis, mostraram ser influenciadores dos mecanismos formadores das chuvas de microescala meteorológica.
\end{abstract}

Palavras-chave: precipitação pluvial, regiões homogêneas, variáveis fisiográficas

\section{Spacial distribution of the rainfall frequencies in the Atlântico hydrographic region, east of Minas Gerais, Brazil}

\begin{abstract}
A study of spacial analysis was carried out with the rainfalls frequencies for the areas of the Atlântico hydrographic region in the eastern part in the State of Minas Gerais. The physiographic variables, such as natural vegetation, topography and wind direction, as well as the total annual rainfall using the geoestatistic Kriging technique to interpret the geospatial distribution of the rainfall frequency groups that represented the areas with homogeneous characteristics. In general, the geostatistic interpolator provided a good estimate of the total annual average rainfall for the studied area, except for the areas where the rainfall station density was relatively low. The physiographic variables and the continuous surface areas of total annual average rainfall was nearly correlated to the space distribution of the rainfall frequencies groups that represented the hydroclimatically homogeneous areas. The topography and the predominant winds at low levels showed to be the cause of the micro scale mechanisms of rainfall spatial distribution.
\end{abstract}

Key words: rainfall, homogeneous areas, physiographic variable 


\section{INTRODUÇÃO}

Desde o século passado o Brasil enfrenta o desafio de compatibilizar seu desenvolvimento com a conservação do meio ambiente. A água é um bom exemplo do impasse, a medida em que a diversidade de segmentos de usuários faz com que sua adequada gestão seja fundamental, a fim de evitar conflitos entre os mesmos, caso em que a mediação do Estado se torna necessária, devendo ser feita por meio de políticas que assegurem a distribuição eqüitativa da água. A Lei 9.433/97, que instituiu a Política Nacional de Recursos Hídricos no Brasil, tem-se constituído em uma excelente experiência, ora vivenciada no País, a fim de otimizar o uso da água e a adoção de medidas voltadas à sua conservação.

A gestão de recursos hídricos é a forma pela qual se busca equacionar e resolver questões de escassez. Para isto, são convenientes procedimentos integrados de planejamento e administração. Para o planejamento adequado dos recursos hídricos, é inevitável se dispor de instrumentos que permitam a quantificação de sua disponibilidade e possam constituir fundamento para sua adequada gestão. Neste sentido, a delimitação e a justificativa da distribuição espacial das regiões com padrões homogêneos da freqüência de chuvas, constituem mecanismo de suporte essencial para a concretização desta meta.

A chuva é um dos elementos climáticos mais diretamente relacionados à produção agrícola, devido ao seu caráter aleatório aumentando, em conseqüência, os riscos na programação das atividades do setor agrícola.

A delimitação das regiões hidroclimaticamente homogêneas significa não apenas estabelecer os indicadores do potencial do meio físico e biológico para a região em estudo mas, também, registrar e delimitar as áreas de padrões homogêneos de atividades agrícolas e dos recursos naturais nela existentes (Sediyama et al., 2001).

Com o presente trabalho, objetivou-se analisar os totais de chuva média anual, utilizando-se o interpolador geoestatístico Kriging ordinário e verificar, por intermédio da variância, a acurácia da superfície contínua obtida. Procurou-se, também, estudar a distribuição espacial dos grupos que representam as regiões com características homogêneas de freqüência de chuvas na região hidrográfica do Atlântico, trecho Leste, no Estado de Minas Gerais, obtidos por Melo Júnior (2003) utilizando-se o método multivariado de agrupamento de Ward Júnior (1963), por intermédio da análise espacial de superfície contínua de chuva média anual e das variáveis fisiográficas de orografia, vegetação natural e direção predominante dos ventos a baixos níveis.

\section{MATERIAL E MÉTODOS}

\section{Região de estudo}

Conforme a Figura 1, a região de estudo abrange a região hidrográfica do Atlântico, trecho Leste no Estado de Minas Gerais, formada pelas bacias hidrográficas dos rios Doce, Jequitinhonha, Mucuri, Paraíba do Sul, e Pardo e das denominadas Bacias do Leste (rios Itabapoana, Itapemirim,
São Mateus, Itanhém, Jucuruçu e Buranhém). Representa, aproximadamente, $21 \%$ da região Sudeste do País e se localiza entre os paralelos $14^{\circ} 58^{\prime} 54^{\prime \prime}$ e $22^{\circ} 22^{\prime} 47^{\prime \prime} \mathrm{S}$, e os meridianos de $39^{\circ} 51^{\prime} 31^{\prime \prime}$ e $44^{\circ} 40^{\prime} 2$ ' $\mathrm{W}$, cuja altitude média é de $651,3 \mathrm{~m}$, além de uma área de $193.733,0 \mathrm{~km}^{2}$, aproximadamente.

Apresentam-se, ainda na Figura 1, os grupos que reproduzem as regiões com características homogêneas de freqüência de chuvas na região hidrográfica do Atlântico, trecho leste, no Estado de Minas Gerais, obtidos por Melo Júnior (2003), utilizando-se o método multivariado de agrupamento, proposto por Ward Júnior (1963).

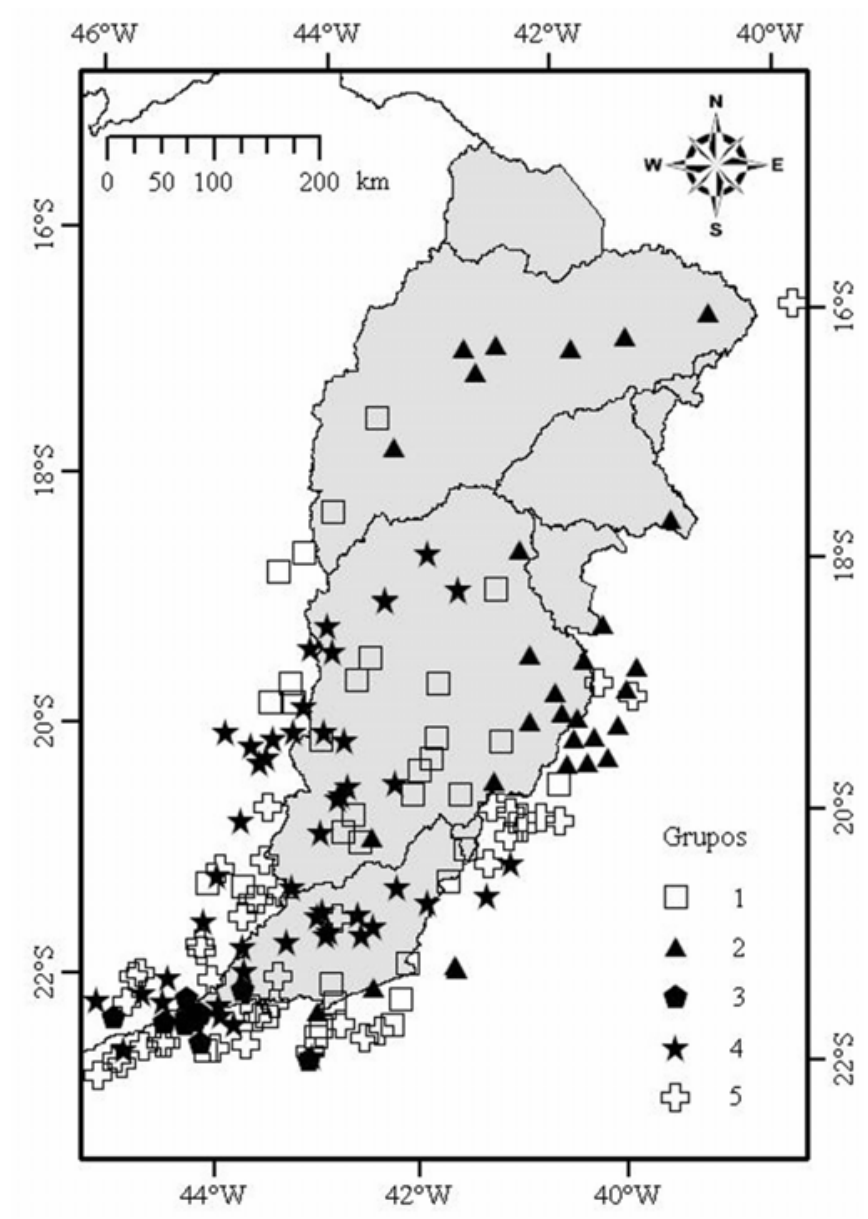

Figura 1. Região hidrográfica de estudo e grupos homogêneos de freqüência de chuvas obtidos por Melo Júnior (2003), por meio do método de agrupamento de Ward Júnior (1963)

\section{Base de dados e aplicativos}

As séries de dados de chuva utilizadas neste estudo, foram obtidas junto à Agência Nacional de Águas - ANA, a partir do sistema de informações hidrológicas (Hidroweb, 2003).

As estações pluviométricas foram espacializadas obtendose, então, a distribuição geoespacial das estações na região. Após a análise da distribuição geoespacial foram selecionadas 163 estações pluviométricas com 30 anos de dados, geograficamente distribuídas, abrangendo toda a região em estudo e áreas vizinhas, obtidas por meio de um buffer, a uma 
distância de $50 \mathrm{~km}$ do limite da região hidrográfica.

Utilizou-se a base vetorial de dados constituída pelos vetores da região hidrográfica e de hidrografia. Obtiveram-se os vetores da região hidrográfica e de hidrografia junto ao Instituto Mineiro de Gestão das Águas (IGAM, 2003), em escalas de 1:100.000 e 1:50.000, respectivamente, em que o responsável pelo geoprocessamento foi o próprio IGAM. O vetor de vegetação natural foi obtido junto ao programa integrado de uso da tecnologia de geoprocessamento pelos órgãos do Estado de Minas Gerais (Geominas, 2003), em escala 1:3.000.000, respondendo pelo geoprocessamento a Companhia de Processamento de Dados do Estado de Minas Gerais (Prodemge).

As séries de dados diários de direção do vento de 52 localidades no Estado de Minas Gerais, nos horários sinóticos de 12, 18 e $24 \mathrm{TMG}$, foram fornecidas em fita magnética, pelo Instituto Nacional de Meteorologia (INMET), com diferentes períodos, desde o ano 1961 até 1978. Esses dados, obtidos a partir de anemógrafos e cataventos do tipo Wild com o sensor instalado a $10 \mathrm{~m}$ de altura, foram processados e submetidos a testes de controle de qualidade pelos pesquisadores do Instituto Nacional de Pesquisas Espaciais (INPE).

A base de dados matricial (raster) utilizada foi o modelo digital de elevação (MDE) ou orografia, obtido junto ao Serviço de Pesquisa Geológica dos EUA (USGS, 2003), com resolução espacial de $1 \mathrm{~km}^{2}$, para toda a região hidrográfica em estudo.

Para a análise geoespacial e geoestatística utilizou-se o Sistema de Informação Geográfica, ArcGIS ${ }^{\circledR}$ 8.1, desenvolvido pelo Enviromental Systems Research Institute - ESRI, como ferramenta de modelagem geoestatística e de representação geoespacial dos dados.

\section{Interpolação dos totais de chuva}

Os totais de chuva média anual das 163 estações pluviométricas com 30 anos de dados foram espacializados por meio do Sistema de Informação Geográfica, $\operatorname{ArcGIS}^{\circledR}$ 8.1, utilizando-se o interpolador geoestatístico Kriging Ordinário, apresentado no item a seguir.

O modelo do semivariograma utilizado e ajustado foi o exponencial, com base nos parâmetros experimentais e raio de busca variável de 72 pontos, sem limitação de distância.

O mapa temático (raster) dos totais de chuva média anual e o mapa (raster) das correspondentes variâncias minimizadas do erro, denominadas variâncias de krigagem ordinária, foram gerados utilizando-se uma resolução espacial de $1 \mathrm{~km}^{2}$. Obteve-se o mapa de variâncias de krigagem ordinária com a finalidade de se informar sobre a confiança dos valores interpolados na área de interesse.

Utilizou-se o mapa temático dos totais de chuva média anual, na tentativa de interpretar a distribuição geoespacial dos grupos que representam as regiões com características homogêneas de freqüência de chuvas.

\section{Krigagem ordinária}

Considerando-se a superfície sobre a qual se observaram os totais de chuva média anual, $\mathrm{Z}$, em $\mathrm{n}$ pontos distintos, com coordenadas representadas pelo vetor $\mathrm{X}$, tem-se um conjun- to de valores $\left[\mathrm{Z}\left(\mathrm{X}_{\mathrm{i}}\right), \mathrm{i}=1,2, \ldots, \mathrm{n}\right]$, em que $\mathrm{X}_{\mathrm{i}}$, identifica uma posição em duas dimensões, representada pelos pares de coordenadas $\left(\mathrm{x}_{\mathrm{i}}, \mathrm{y}_{\mathrm{i}}\right)$. Supondo que se pretende estimar o valor de $\mathrm{Z}$ no ponto $\mathrm{X}_{0}$, conclui-se que o valor desconhecido de $\mathrm{Z}\left(\mathrm{X}_{0}\right)$ pode ser estimado a partir de uma combinação linear dos $\mathrm{n}$ valores observados, adicionado a um parâmetro, $\lambda_{0}$ (Journel, 1988).

$$
\hat{\mathrm{Z}}_{\mathrm{X}_{0}}=\lambda_{0}+\sum_{\mathrm{i}=1}^{\mathrm{n}} \lambda_{\mathrm{i}} \mathrm{Z}\left(\mathrm{X}_{\mathrm{i}}\right)
$$

Deseja-se um estimador não-tendencioso, isto é,

$$
\mathrm{E}\left[\mathrm{Z}_{\mathrm{X}_{0}}-\hat{\mathrm{Z}}_{\mathrm{X}_{0}}\right]=0
$$

A Eq. 2 impõe que as duas médias sejam iguais; assim, substituindo-se a Eq. 1 em 2, obtém-se

$$
\mathrm{E}\left[\mathrm{Z}_{\mathrm{X}_{0}}\right]=\mathrm{E}\left[\lambda_{0}+\sum_{\mathrm{i}=1}^{\mathrm{n}} \lambda_{\mathrm{i}} \cdot \mathrm{Z}\left(\mathrm{X}_{\mathrm{i}}\right)\right] \Rightarrow \mathrm{m}=\lambda_{0}+\sum_{\mathrm{i}=1}^{\mathrm{n}} \lambda_{\mathrm{i}} \cdot \mathrm{m}
$$

A krigagem ordinária não requer o prévio conhecimento da média m e, neste caso, para que a igualdade da Eq. 3 seja satisfeita, é necessário que

$$
\lambda_{0}=0 \quad \text { e } \quad \sum_{i=1}^{\mathrm{n}} \lambda_{\mathrm{i}}=1
$$

portanto, o estimador de krigagem ordinária é

$$
\hat{Z}_{X_{0}}=\sum_{i=1}^{n} \lambda_{i} Z\left(X_{i}\right), \operatorname{com} \sum_{i=1}^{n} \lambda_{i}=1
$$

Journel (1988) demonstra que, minimizando a variância do erro, $\operatorname{Var}\left[Z_{\mathrm{X}_{0}}-\hat{Z}_{\mathrm{X}_{0}}\right]$, sob a condição que

$\sum_{\mathrm{i}=1}^{\mathrm{n}} \lambda_{\mathrm{i}}=1$, os pesos $\lambda_{\mathrm{i}}$ serão obtidos a partir do seguinte sistema de equações, denominado sistema de krigagem ordinária:

$$
\left\{\begin{array}{l}
\sum_{j=1}^{n} \lambda_{j} C\left(X_{i}, X_{j}\right)-\alpha=C\left(X_{i}, X_{0}\right) \quad \text { para } i=1,2, \ldots, n \\
\sum_{j=1}^{n} \lambda_{j}=1
\end{array}\right.
$$

em que:

$\mathrm{C}\left(\mathrm{X}_{\mathrm{i}}, \mathrm{X}_{\mathrm{j}}\right)$ - função covariância correspondente a um vetor, $\mathrm{h}$, com origem em $\mathrm{X}_{\mathrm{i}}$ e extremidade em $\mathrm{X}_{\mathrm{j}}$

$\mathrm{C}\left(\mathrm{X}_{\mathrm{i}}, \mathrm{X}_{0}\right)$ - função covariância correspondente a um vetor, $\mathrm{h}$, com origem em $\mathrm{X}_{\mathrm{i}}$ e extremidade no ponto a ser estimado, $\mathrm{X}_{0}$

$\alpha$ - multiplicador de Lagrange necessário para minimização da variância do erro.

A correspondente variância minimizada do erro, denominada 'variância de krigagem ordinária', $\sigma_{\mathrm{ko}}^{2}$, é dada pela Eq. 6.

R. Bras. Eng. Agríc. Ambiental, v.10, n.2, p.417-425, 2006. 


$$
\sigma_{\mathrm{ko}}^{2}=\operatorname{Var}\left[\mathrm{Z}_{\mathrm{X}_{0}}-\hat{\mathrm{Z}}_{\mathrm{X}_{0}}\right]=\mathrm{C}(0)-\sum_{\mathrm{i}=1}^{\mathrm{n}} \lambda_{\mathrm{i}} \mathrm{C}\left(\mathrm{X}_{\mathrm{i}}, \mathrm{X}_{0}\right)-\alpha
$$

\section{Variáveis fisiográficas}

Utilizaram-se as variáveis fisiográficas vegetação natural, orografia e direção do vento a baixos níveis, com o intuito de interpretar e justificar a distribuição geoespacial dos grupos que representam as regiões com características homogêneas de freqüência de chuvas, na região hidrográfica em estudo.

O mapa temático de vegetação natural para região hidrográfica, obtido junto ao Geominas (2003), possuía quatro atributos de classe: caatinga, campo rupestre de altitude, cerrado e campo cerrado e floresta atlântica. Como a vegetação natural é conseqüência do clima da região, esta foi utilizada na tentativa de se interpretar a distribuição geoespacial dos grupos obtidos por meio da análise multivariada.

O mapa de orografia para a região hidrográfica em estudo, obtido por meio de informações de satélite junto ao USGS (2003), foi utilizado na tentativa de se interpretar a distribuição geoespacial dos grupos, pois o relevo é uma variável fisiográfica que influencia o mecanismo fundamental pelo qual se produz a ascensão do ar úmido, gerando as chamadas chuvas orográficas.

A média anual do percentual das direções do vento para a região hidrográfica em estudo, obtida junto ao INMET, foi espacializada pontualmente, na forma de gráfico de barras. A direção do vento a baixos níveis foi empregada na tentativa de se interpretar a distribuição geoespacial dos grupos, representando as possíveis tendências de atuação dos mecanismos de grande, meso e microescala meteorológica.

\section{RESULTADOS E DISCUSSÃO}

\section{Interpolação dos totais de chuva}

As espacializações dos totais de chuva média anual PMA $(\mathrm{mm})$ para a região hidrográfica em estudo obtida por meio do método de interpolação linear kriging ordinário e dos grupos obtidos segundo o método de agrupamento de Ward, são apresentadas na Figura 2, na qual se observa que os totais de chuva média anual estimados variaram entre 2.340 a $760 \mathrm{~mm}$ do extremo Sul ao Nordeste da região hidrográfica, respectivamente, enquanto sua média é igual a $1.098 \mathrm{~mm}$, com desvio-padrão de $218 \mathrm{~mm}$. O valor do total de chuva média anual estimado por meio da krigagem ordinária referente ao pico do histograma de freqüência (moda) é igual a 891,6 mm, indicando que a distribuição espacial de freqüência dos totais de chuva possui assimetria positiva. As considerações apresentadas nos próximos parágrafos, referem-se à Figura 2.

As delimitações das áreas nos mapas (Figuras 2, 4, 5 e 6), por linhas tracejadas, foram feitas apenas para permitir uma visualização melhor dos grupos, sem nenhum critério objetivo, não representando isolinhas.

Para o primeiro grupo, os totais de chuva média anual variam em torno de 1.355 a $1.088 \mathrm{~mm}$, em áreas que se estendem do Sudeste e do Centro ao Noroeste, na região hidrográfica. Na sobreposição do quarto grupo em áreas ao Sul,

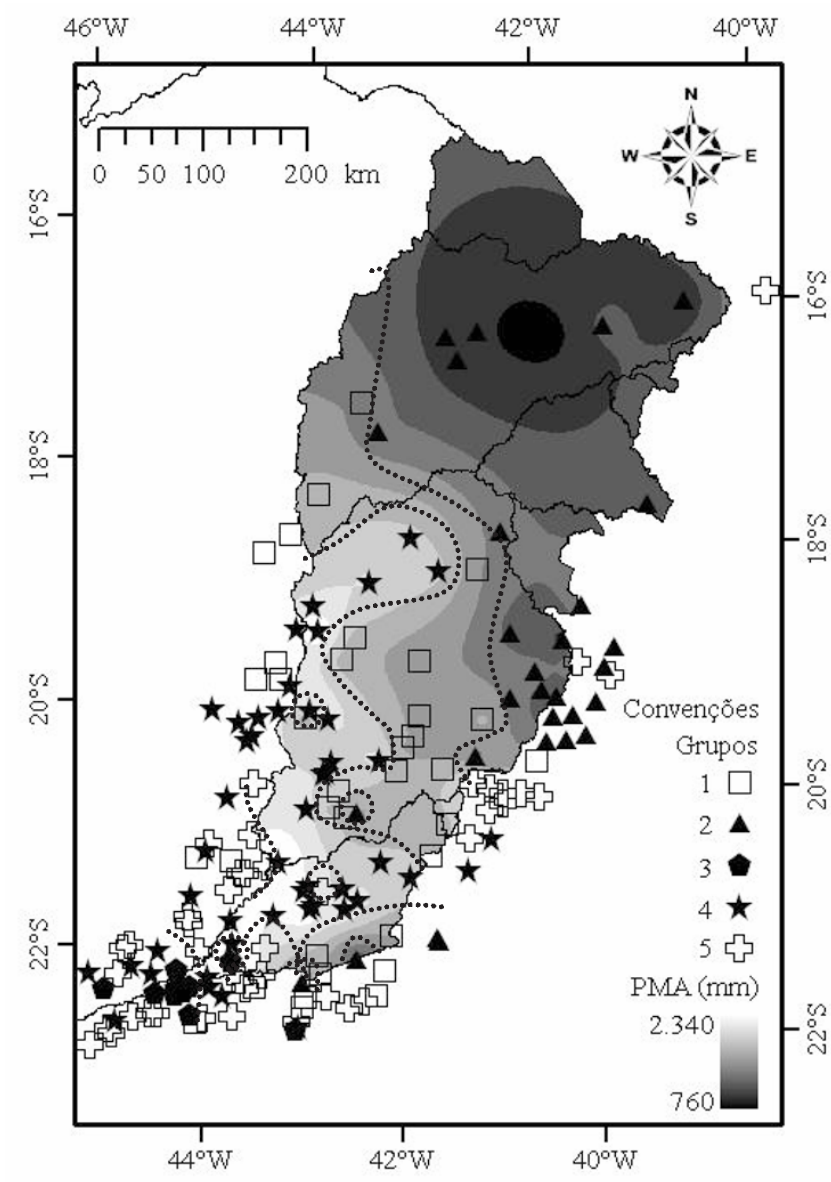

Figura 2. Totais de chuva média anual, PMA $(\mathrm{mm})$, para a região hidrográfica, obtida por intermédio do método de interpolação linear "kriging" ordinário, e grupos obtidos segundo o método de agrupamento de Ward Júnior (1963)

na região hidrográfica, observam-se totais variando em torno de 1.252 a $1.198 \mathrm{~mm}$, ao passo que, em uma pequena área isolada a Oeste, observa-se um total igual a $1.251 \mathrm{~mm}$, referente ao valor estimado para a estação pluviométrica 01943007 (Santa Bárbara, MG); para o segundo grupo, os totais de chuva média anual variam em torno de 1.086 a $760 \mathrm{~mm}$, em áreas que se estendem do Leste ao Norte e Nordeste, na região hidrográfica. Observam-se, na sobreposição do primeiro grupo, em áreas ao Sul da região hidrográfica, totais variando em torno de 1.127 a $935 \mathrm{~mm}$ e em uma pequena área isolada ao Centro, um total igual a $1.189 \mathrm{~mm}$, referente ao valor estimado para a estação pluviométrica 02042016 (São Miguel do Anta, MG).

Para o terceiro grupo os totais de chuva média anual variam em torno de 2.329 a $1.940 \mathrm{~mm}$, em uma pequena área situada no extremo Sul, na região hidrográfica. Na sobreposição do quarto grupo, em uma pequena área isolada situada no extremo Sul, na região hidrográfica, tem-se o total igual a $1.954 \mathrm{~mm}$, concernente ao valor estimado para a estação pluviométrica 02243202 (Fazenda São Gabriel, MG).

Para o quarto grupo, os totais de chuva média anual variam em torno de 1.738 a $1.328 \mathrm{~mm}$, em áreas que se estendem do extremo Sul ao Sudoeste e Oeste, na região hidrográfica.

Para o quinto grupo, os totais de chuva média anual variam 
em torno de 1.451 a $1.389 \mathrm{~mm}$ e 1.520 a $1.491 \mathrm{~mm}$, em pequenas áreas situadas no extremo Sul e Sudoeste na região hidrográfica, respectivamente. Em uma pequena área isolada, situada no Sul constata-se, na região hidrográfica, um total igual a $1.415 \mathrm{~mm}$, referente ao valor estimado para a estação pluviométrica 02143001 (Guarani, MG).

Para os segundo, primeiro, quarto, quinto e terceiro grupos, os totais de chuva média anual variam em torno de 760 a $1.189 \mathrm{~mm}, 1088$ a $1.355 \mathrm{~mm}, 1.328$ a $1.738 \mathrm{~mm}, 1.389$ a $1.520 \mathrm{~mm}$ e 1.941 a $2.329 \mathrm{~mm}$, respectivamente. Com base nos totais de chuva média anual dos grupos obtidos por meio do método de agrupamento proposto por Ward, nota-se coerência nos intervalos de variação, além de sobreposição dos grupos: segundo no primeiro e primeiro no quarto. O intervalo de variação do quarto grupo contém o do quinto. As áreas do quinto grupo mostram tratar-se de regiões que possuem diferenciações microclimáticas em relação às regiões vizinhas. O intervalo de variação do terceiro grupo não se sobrepõe a nenhum outro e apresenta um limite inferior bem superior ao limite superior do quarto grupo.

A Tabela 1 apresenta os valores máximos, mínimos, médios e desvios-padrão dos totais de chuva média anual, estimados para todas as bacias hidrográficas que compõem a região de estudo. Constata-se que as bacias hidrográficas situadas no Sul e Sudeste apresentam os maiores valores médios dos totais de chuva média anual, enquanto as situadas no Norte e Nordeste apresentam os menores valores.

A variância de krigagem ordinária referente aos totais de chuva média anual estimados utilizando-se o interpolador kriging ordinário (Figura 2) para a região hidrográfica, é apresentada na Figura 3, por meio da qual se tem que os maiores valores da variância de krigagem ocorrem em áreas situadas no Nordeste, Noroeste e Norte da região hidrográfica, em que a densidade de estações pluviométricas é praticamente nula. Os valores intermediários da variância de krigagem ocorrem em áreas situadas no Nordeste, Noroeste e Centro da região hidrográfica, onde a densidade de estações é pequena em relação à densidade média de estações pluviométricas da região hidrográfica. Os menores valores da variância de krigagem ocorrem em áreas situadas no Leste,

Tabela 1. Valores máximos, mínimos, médios e desvios-padrão (s) dos totais de chuva média anual, estimados para todas as bacias hidrográficas que compõem a região hidrográfica

\begin{tabular}{lcccc}
\hline \multirow{2}{*}{ Bacias hidrográficas } & \multicolumn{4}{c}{ Totais de chuva média anual (mm) } \\
\cline { 2 - 5 } & Mínimo & Máximo & Médio & s \\
Rio Pardo & 826,8 & 945,1 & 893,9 & 24,6 \\
Rio Mucuri & 853,6 & $1.039,0$ & 938,2 & 36,6 \\
Rio Jequitinhonha & 759,5 & $1.312,5$ & 944,4 & 123,7 \\
Rio Doce & 883,1 & $1.597,6$ & $1.239,2$ & 144,5 \\
Rio Paraíba do Sul & 923,4 & $2.340,7$ & $1.411,2$ & 174,5 \\
Rio Buranhém* & 904,3 & 941,3 & 920,1 & 8,4 \\
Rio Jucuruçu* & 906,5 & 948,1 & 923,6 & 10,4 \\
Rio Itanhém* & 892,5 & 934,7 & 913,8 & 9,2 \\
Rio São Mateus* & 948,7 & $1.052,5$ & $1.005,1$ & 15,8 \\
Rio Itapemirim* & $1.202,6$ & $1.226,0$ & $1.214,3$ & 5,6 \\
Rio Itabapoana * & $1.264,8$ & $1.410,6$ & $1.321,0$ & 37,4 \\
\hline
\end{tabular}

${ }^{*}$ Conjunto de bacias hidrográficas denominadas Bacias do Leste
Oeste, Sudeste, Sudoeste, Sul e extremo Sul, que possuem maior densidade de estações pluviométricas.

O mapa temático da variância de krigagem ordinária, ou de predição, quantifica a incerteza estatística de cada valor estimado do total de chuva média anual, para cada célula do mapa temático apresentado na Figura 2. Na Figura 3 constata-se que as localizações próximas aos pontos geralmente possuem variâncias menores que as mais distantes, uma característica da variância de krigagem ordinária, indicando que a maior variância representa, também, a maior incerteza para a predição.

Os totais de chuva média anual para todas as áreas referentes às bacias hidrográficas dos rios Buranhém, Juruçu, Itanhém e Pardo, não são confiáveis devido à alta variabilidade observada por meio da variância de krigagem (Figura 3). Esta alta variabilidade é também constatada em grande parte das áreas que compõem as bacias hidrográficas dos rios Mucuri e Jequitinhonha, e em pequena parte da área que forma a bacia hidrográfica do Rio São Mateus. Para as outras áreas que compõem as demais bacias hidrográficas, os totais de chuva média anual são considerados confiáveis, com base na variância de krigagem. Na maioria das vezes, as variâncias elevadas observadas ocorrem em virtude da extrapolação obtida por meio do interpolador kriging ordinário, caso este observado no Norte, Noroeste e Nordeste da região hidrográfica.

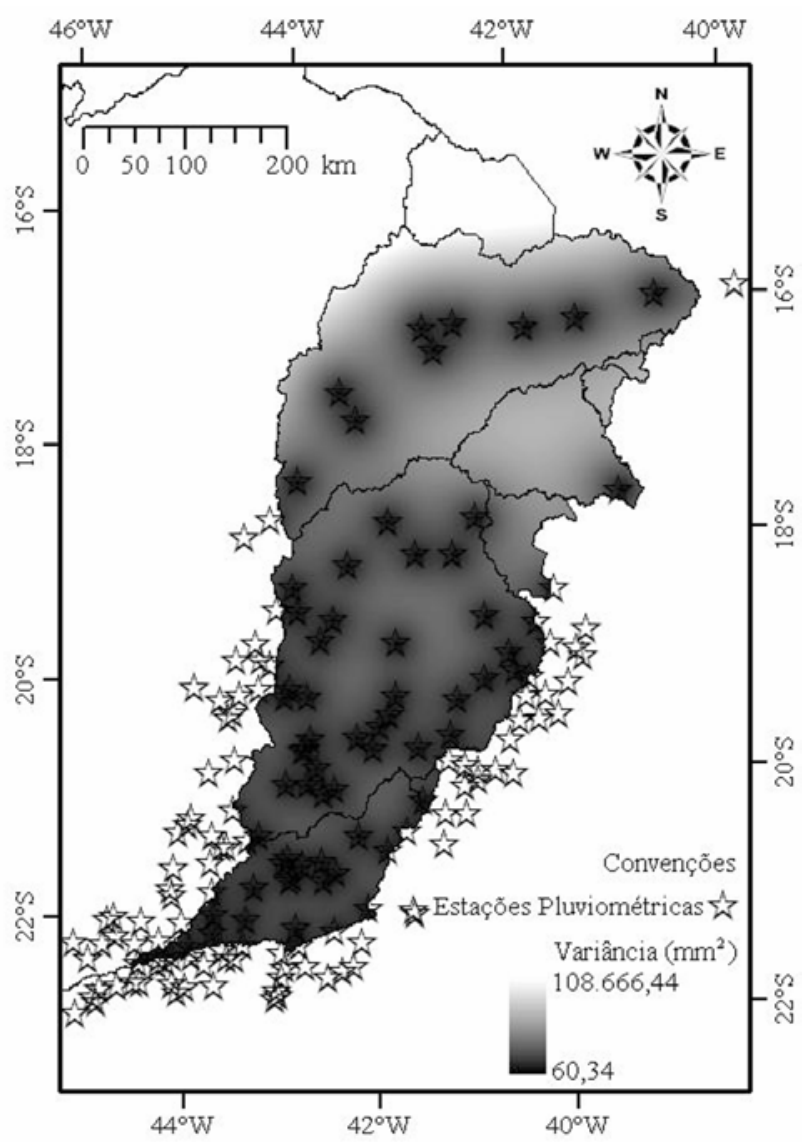

Figura 3. Variância de krigagem referente aos totais de chuva média anual estimados por intermédio do interpolador linear kriging ordinário, para a região hidrográfica 


\section{Variáveis fisiográficas}

Com o propósito de se interpretar a distribuição geoespacial dos grupos obtidos por meio da análise agrupamento utilizando-se o método proposto por Ward Júnior (1963), para o critério de classificação mesoclimático (Melo Júnior, 2003), utilizam-se as variáveis fisiográficas orografia, vegetação natural e direção do vento a baixas altitudes, as quais possuem relações diretas ou indiretas, com as classes de freqüência de chuvas diárias na região hidrográfica, de fundamental importância para a interpretação da distribuição espacial dos grupos com características homogêneas de freqüência de chuvas.

A orografia espacializada como variável fisiográfica, obtida por meio do USGS (2003), e os grupos, segundo o método de agrupamento proposto por Ward para a região hidrográfica, são apresentados na Figura 4, observando-se que as cotas altimétricas da orografia variam entre 25 a $2.863 \mathrm{~m}$ na região hidrográfica e, também, que a média altimétrica é igual a $651 \mathrm{~m}$. As considerações apresentadas nos próximos parágrafos, referem-se à Figura 4.

Para o primeiro grupo, as cotas altimétricas da orografia variam em torno de 229 a 909 m, em áreas que se estendem do Sudeste, Centro ao Noroeste na região hidrográfica. Nas sobreposições do quarto grupo, em áreas ao Sul da região

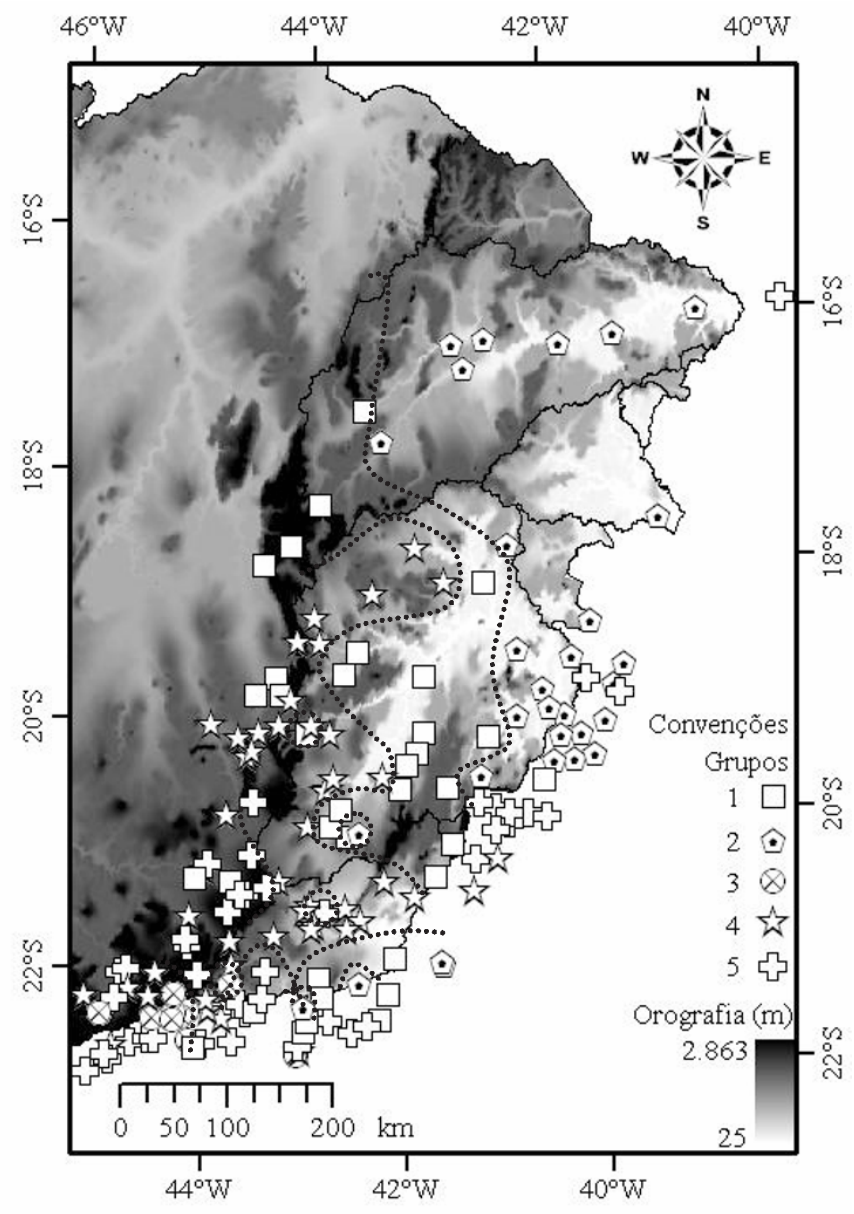

Figura 4. Orografia (m) espacializada como variável fisiográfica obtida por meio do USGS (2003) e grupos, segundo o método de agrupamento proposto por Ward Júnior (1963), para a região hidrográfica hidrográfica, observam-se cotas variando em torno de 260 a $572 \mathrm{~m}$ e, em uma pequena área isolada ao Oeste, uma cota igual a $778 \mathrm{~m}$, referente à estação pluviométrica 01943007.

Para o segundo grupo as cotas altimétricas da orografia variam por volta de 73 a 649 m em áreas que se estendem do Leste ao Norte e Nordeste, na região hidrográfica. Nas sobreposições do primeiro grupo, em áreas ao Sul da região hidrográfica, observam-se cotas variando de 25 a $271 \mathrm{~m}$ e, em uma pequena área isolada ao Centro, constata-se uma cota igual a $684 \mathrm{~m}$, referente à estação pluviométrica 02242016 .

Para o terceiro grupo as cotas altimétricas da orografia se estabelecem por volta de 734 a $1.426 \mathrm{~m}$, em uma pequena área situada no extremo Sul na região hidrográfica. $\mathrm{Na}$ sobreposição do quarto grupo, em uma pequena área isolada situada no extremo Sul na região hidrográfica, nota-se uma cota igual a $1.043 \mathrm{~m}$ referente à estação pluviométrica 02243202 .

Para o quarto grupo as cotas altimétricas da orografia variam em torno de 274 a $1.519 \mathrm{~m}$, em áreas que se estendem do extremo Sul ao Sudoeste e Oeste, na região hidrográfica.

Para o quinto grupo as cotas altimétricas da orografia variam em torno de 449 a 649 m e 988 a 1.060 m, em pequenas áreas situadas no extremo Sul e Sudoeste na região hidrográfica, respectivamente. Em uma pequena área isolada situada no Sul na região hidrográfica, observa-se uma cota igual a $439 \mathrm{~m}$, correspondente à estação pluviométrica 02143001 .

Para os segundo, primeiro, quarto, quinto e terceiro grupos, as cotas altimétricas da orografia variam em torno de 25 a 684 m, 229 a 909 m, 274 a 1.519 m, 439 a 1.060 m e 734 a $1.426 \mathrm{~m}$, respectivamente. Com base nas cotas da orografia, observa-se certa coerência nos intervalos de variação e sobreposições dos grupos: segundo no primeiro e primeiro no quarto. O intervalo de variação do quarto grupo contém os grupos terceiro e quinto.

Numa comparação entre as distribuições espaciais da orografia (Figura 4) e dos totais de chuva média anual (Figura 2), verifica-se a existência de uma correlação entre ambos, isto é, para as áreas que possuem maiores cotas altimétricas situadas no extremo Sul e Sudoeste, Oeste, Centro-Oeste e Sudeste, que representam as cadeias de montanha das serras da Mantiqueira, Espinhaço, Gavião e Caparaó, respectivamente; os totais de chuva observados são elevados e superiores a $1.300 \mathrm{~mm}$ anuais enquanto para áreas de menores cotas representadas pelos vales dos rios Jequitinhonha, Mucuri, Doce e Pomba, os totais de chuva se apresentam baixos e inferiores a $1.300 \mathrm{~mm}$ anuais. Esta consideração leva ao indício de que a orografia influencia os mecanismos formadores das chuvas de microescala meteorológica na região, visto que as chuvas orográficas são resultante da ascensão mecânica de correntes de ar úmido sobre barreiras naturais, como as montanhas.

A vegetação natural espacializada como variável fisiográfica, obtida do Geominas (2003) e os grupos por intermédio do método de agrupamento proposto por Ward, para a região hidrográfica, são apresentados na Figura 5. Como a vegetação natural é conseqüente do clima da região, esta é 
utilizada como variável fisiográfica, na tentativa de interpretar a distribuição espacial dos grupos obtidos por meio da análise de agrupamento, utilizando-se o método proposto por Ward, para o critério de classificação mesoclimático. As considerações feitas nos parágrafos seguintes se referem à Figura 5.

O primeiro grupo ocupa áreas referentes às classes de vegetação natural: cerrado e campo cerrado, campo rupestre de altitude e floresta atlântica. A ocorrência do grupo na classe cerrado e campo cerrado se situa em uma área isolada a Noroeste, na região hidrográfica, enquanto a classe campo rupestre de altitude se localiza em áreas isoladas a Oeste e Noroeste e a classe floresta atlântica se encontra em áreas no Centro-Oeste, Centro e Sudeste.

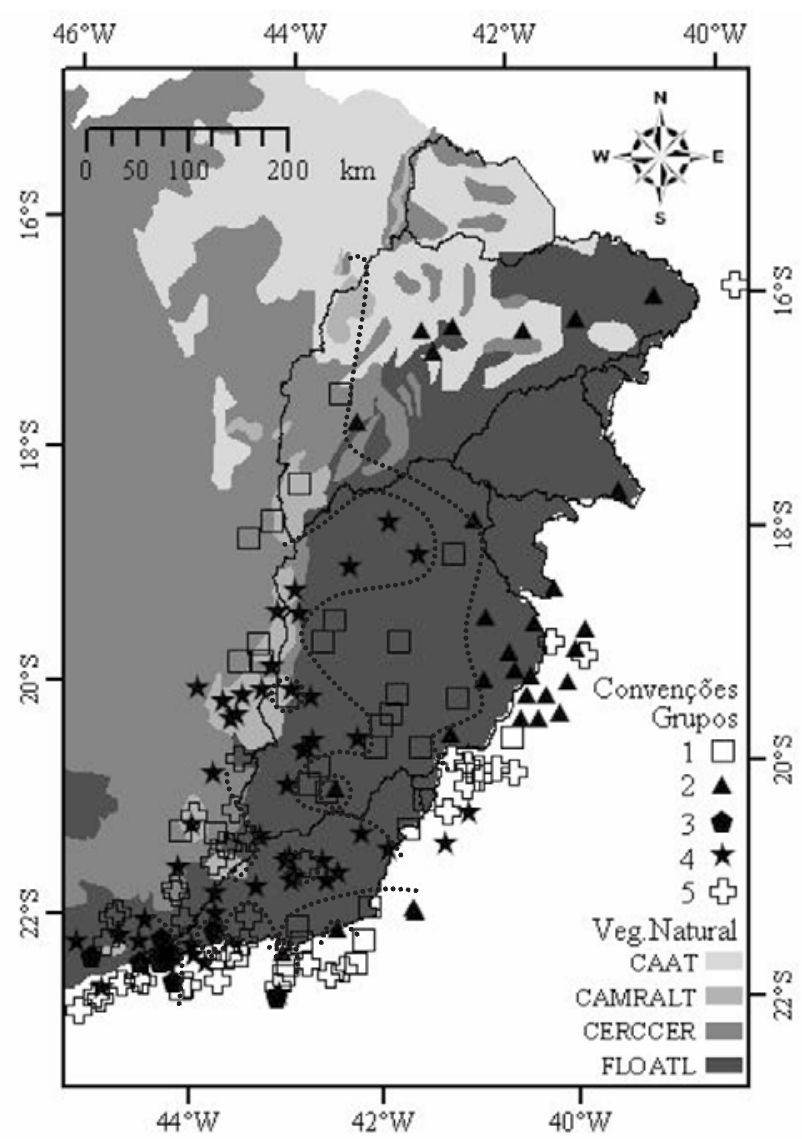

Figura 5. Vegetação natural (CAAT, Caatinga; CAMRALT, Campo Rupestre de Altitude; CERCCER, Cerrado e Campo Cerrado; FLOATL, Floresta Atlântica) espacializada como variável fisiográfica obtida por meio do Geominas (2003) e grupos, segundo o método de agrupamento proposto por Ward Júnior (1963), para a região hidrográfica

O segundo grupo, por sua vez, ocupa áreas referentes às classes de vegetação natural: caatinga, cerrado e campo cerrado e floresta atlântica. A ocorrência do grupo na classe caatinga se situa em áreas a Nordeste, extremo Noroeste e Norte, na região hidrográfica, enquanto a classe cerrado e campo cerrado está em uma área isolada a Noroeste e a classe floresta atlântica faz parte de áreas a Nordeste, Centro, Sudeste e Sul.

O terceiro grupo ocupa áreas referentes à classe de vege- tação natural floresta atlântica ao extremo Sul, na região hidrográfica.

O quarto grupo ocupa áreas referentes às classes de vegetação natural: campo rupestre de altitude e floresta atlântica. A ocorrência do grupo na classe campo rupestre de altitude se localiza em uma área isolada a Oeste na região hidrográfica e, na classe floresta atlântica, se situa em áreas no Oeste, Centro-Oeste, Sudoeste, Sul e extremo Sul.

$\mathrm{O}$ quinto grupo se encontra em áreas referentes às classes de vegetação natural: cerrado e campo cerrado e floresta atlântica. A ocorrência do grupo na classe cerrado e campo cerrado ocorre em uma área isolada a Sudoeste na região hidrográfica, enquanto na classe floresta atlântica se situa em áreas ao Sul e extremo Sul.

Fazendo-se uma análise visual do mapa temático de vegetação natural, na tentativa de se interpretar a distribuição espacial dos grupos obtidos por meio da análise de agrupamento utilizando-se o método proposto por Ward Júnior (1963), observa-se que somente as classes caatinga e cerrado e campo cerrado podem justificar a ocorrência do segundo grupo ao Norte, Nordeste e Noroeste da região hidrográfica. Não se constata relação entre as demais classes de vegetação e grupos.

A direção do vento a baixos níveis, espacializada sob a forma de gráficos de barra como variável fisiográfica, a orografia e os grupos obtidos por meio do método de agrupamento proposto por Ward Júnior (1963) para a região hidrográfica, são apresentados na Figura 6.

Como o escoamento (direção preferencial do vento) a $850 \mathrm{hPa}(\approx 1.500 \mathrm{~m})$ sobre o Estado de Minas Gerais é, praticamente, o mesmo da superfície, tanto no verão quanto no inverno (Vianello \& Maia, 1986), a direção do vento a baixos níveis pode representar um indicativo da configuração do escoamento na região hidrográfica. Assim, esta é utilizada como variável fisiográfica na tentativa de se interpretar a distribuição espacial dos grupos obtidos por meio da análise agrupamento, utilizando-se o método proposto por Ward Júnior (1963) para o critério de classificação mesoclimático. As considerações apresentadas nos próximos parágrafos se referem à Figura 6.

Após realizada uma análise do mapa temático de direção do vento a baixos níveis observa-se, nas áreas que se estendem do Centro ao Norte da região hidrográfica, direções predominantes E, SE e N e, nas áreas situadas a Sudoeste e Oeste da região hidrográfica, direções predominantes NW, NE e E que, possivelmente, caracterizam a influência do Anticiclone do Atlântico Sul no escoamento da região hidrográfica. Nas áreas situadas a Sudeste, Sudoeste e Sul, observam-se direções predominantes SE, E e $\mathrm{S}$, indicando a influência dos ventos alísios, de SE e E, no escoamento da região.

Uma possível relação entre as direções predominantes do vento, a orografia e a distribuição dos grupos, é observada. Primeiro, a distribuição espacial dos grupos está relacionada a grandes e pequenas altitudes, isto é, os grupos que possuem as menores (maiores) freqüências médias absolutas para todas as classes, são observados em áreas com médias a baixas (médias a altas) cotas altimétricas. 


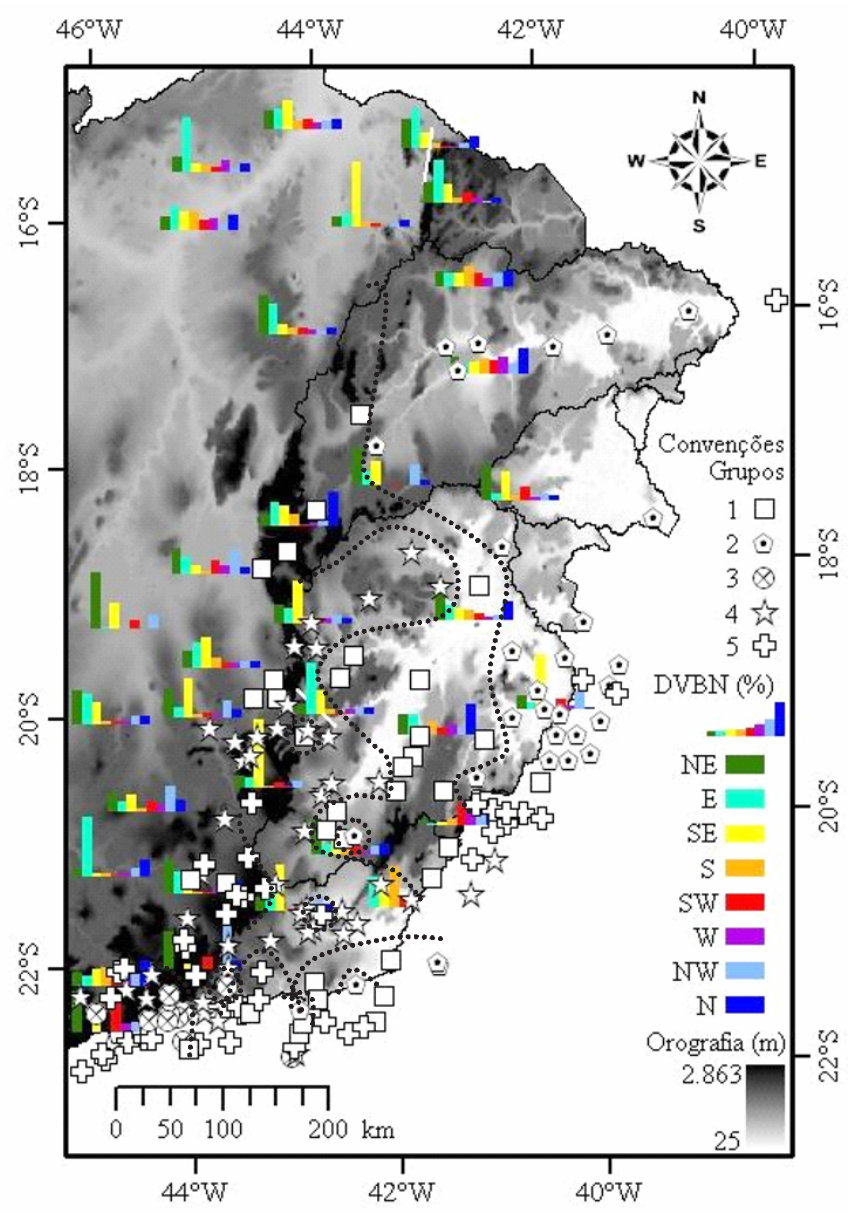

Figura 6. Direção do vento a baixos níveis (DVBN), como variável fisiográfica obtida por intermédio INMET, orografia e grupos, conforme o método de agrupamento proposto por Ward Júnior (1963), para a região hidrográfica

Conforme já mencionado, as direções do vento de SE e E são predominantes nas áreas situadas a Oeste e Sudoeste da região hidrográfica. Em alguns pontos dessas áreas, observa-se uma diferenciação imediata dos grupos situados a sotavento dos situados a barlavento da serra do Espinhaço. Esta diferenciação de grupos a sotavento e a barlavento, associa$\mathrm{da}$ às direções predominantes do vento na região, leva ao indício de que a orografia, juntamente com a direção predominante do vento (indiretamente), influencia o regime de chuvas na região. Esta influência é resultante da ascensão mecânica de correntes de ar úmido sobre barreiras naturais, como as montanhas.

A sotavento da serra do Espinhaço constatam-se pequenas áreas que representam o grupo 1, caracterizado por possuir menores freqüências para todas as classes, em relação aos grupos 4 e 5, situados a barlavento.

Para outra área situada na serra do Caparaó, também se verifica a possível influência orográfica nos grupos situados a barlavento (Estado do Espírito Santo) ou a sotavento (região hidrográfica), embora não exista direção predominante (SE e E) caracterizando a situação.

A direção do vento a baixos níveis, embora visualmente, refletem a circulação dos sistemas de grande escala, sofre grande influência do relevo.
Os sistemas transientes de macroescala meteorológica, Vórtice Ciclônico de Ar Superior (VCAS), Zonas de Convergência do Atlântico Sul (ZCAS), Linhas de Instabilidade e Zonas Frontais são, também, responsáveis pelos regimes pluviométricos na região hidrográfica em estudo; estes são, na maioria das vezes, os grandes influenciadores dos regimes pluviométricos tanto no Sul, onde se observam maiores totais de chuva média anual, quanto no Norte e Nordeste, onde são observados os menores totais. Existem outros sistemas de macroescala que podem influenciar indiretamente os regimes pluviométricos da região hidrográfica em estudo.

Os fenômenos de mesoescala e microescala meteorológica, como os complexos convectivos e as pequenas células convectivas, também promovem, respectivamente, grande influência no regime de chuvas, especificamente no período chuvoso, proporcionando grande variação espacial e temporal dos totais de chuva na região; entretanto, a influência desses sistemas e fenômenos na distribuição espacial dos grupos, obtidos por meio da análise de agrupamento, não será discutida pelo fato de se tratar de estudos específicos da área de Climatologia Dinâmica.

\section{CONCLUSÕES}

1. Em âmbito geral, o interpolador geoestatístico proporcionou boas estimativas dos totais de chuva média anual para a região estudada, exceto para as áreas em que a densidade de estações se apresentou reduzida.

2. A superfície contínua dos totais de chuva anual espacializados, mostrou-se como parâmetro justificador da distribuição espacial dos grupos que representam regiões homogêneas de freqüência de chuvas, na região hidrográfica de estudo.

3. A orografia influencia os mecanismos formadores das chuvas de microescala meteorológica na região hidrográfica de estudo, mostrando tratar-se de uma variável fisiográfica que justifica a distribuição espacial dos grupos que representam as regiões homogêneas de freqüência de chuvas bem como dos totais de chuva anual.

4. Somente as classes caatinga e cerrado e campo cerrado justificaram a ocorrência do segundo grupo ao Norte, Nordeste e Noroeste da região hidrográfica. Não se observou relação entre as demais classes de vegetação e grupos que representam as regiões homogêneas de freqüência de chuvas.

5. Uma relação entre as direções predominantes do vento, a orografia e a distribuição dos grupos que representam as regiões homogêneas de freqüência de chuvas, foi observada.

\section{LITERATURA CITADA}

Geominas. Programa Integrado de Uso da Tecnologia de Geoprocessamento pelos Órgãos do Estado de Minas Gerais. http:// www.geominas.mg.gov.br/. 10 Fev. 2003. 
Hidroweb - Dados Hidrológicos, Séries Históricas; Sistema de Informações Hidrológicas. http://www.hidroweb.ana.gov.br/ HidroWeb/. 05 Jan. 2003.

IGAM-Geoprocessamento; Instituto Mineiro de Gestão das Águas. http://www.igam.mg.gov.br/geo.php. 10 Fev. 2003.

Journel, A. G. Fundamental of geoestatistics in five lessons. California: Stanford Center for Reservoir Forecasting, 1988. 172p.

Melo Júnior, J. C. F. Análise espaço-temporal do regime de chuvas na região hidrográfica do Atlântico, trecho Leste no Estado de Minas Gerais. Viçosa: UFV, 2003. 129p. Tese Doutorado
Sediyama, G. C.; Melo Júnior, J. C. F.; Santos, A. R.; Ribeiro, A.; Hamakawa, P. J.; Costa, L. C.; Costa, J. M. N.; Costa, M. H. Zoneamento agroclimático do cafeeiro (Coffea arábica L.) para o Estado de Minas Gerais. Revista Brasileira de Agrometeorologia, Santa Maria, v.9, n.3, N Especial: Zoneamento Agrícola, p.501-509, 2001.

USGS-United State Geological Survey; Topographic Maps. http:/ /www.mcmcweb.er.usgs.gov/topomaps/. 20 Mar. 2003.

Vianello, R. L.; Maia, L. F. P. G. Estudo preliminar da climatologia dinâmica do Estado de Minas Gerais. Revista Informe Agropecuário, Belo Horizonte, v.12, n.138, p.6-8, 1986.

Ward Júnior, J. H. Hierarchical grouping to optimize an objective function. Journal of the American Statistical Association, Alexandria, v.58, n.301, p.236-244, 1963. 